\title{
Involvement of the mevalonate pathway in the antiproliferative effect of zoledronate on ACHN renal cell carcinoma cells
}

\author{
MEGUMI FUJTA $^{1}{ }^{\text {, MAKIKO TOHI }}{ }^{1}$, KYOKO SAWADA ${ }^{1}$, YASUHIRO YAMAMOTO ${ }^{2}$, \\ TSUTOMU NAKAMURA ${ }^{2}$, TATSUROU YAGAMI ${ }^{2}$, MOTOHIRO YAMAMORI ${ }^{1}$ and NOBORU OKAMURA ${ }^{1}$ \\ ${ }^{1}$ Department of Clinical Pharmacy, School of Pharmacy and Pharmaceutical Sciences, \\ Mukogawa Women's University, Nishinomiya, Hyogo 663-8179; ${ }^{2}$ Department of Pharmaceutical Health Care, \\ Faculty of Pharmaceutical Sciences, Himeji Dokkyo University, Himeji, Hyogo 670-8524, Japan
}

Received November 26, 2011; Accepted January 9, 2012

DOI: $10.3892 /$ or.2012.1683

\begin{abstract}
Renal cell carcinoma (RCC) has been shown to be resistant to chemotherapy and radiotherapy. In order to examine the potential of zoledronate (ZOL), a bisphosphonate, as an anticancer agent, we investigated the effects of $\mathrm{ZOL}$ on RCC cells and the involvement of the mevalonate pathway in antiproliferative effects, as well as the effects of ZOL administration on mice inoculated with RCC. ACHN cells were used and cell viability was measured via intracellular reductase activity. Chromatin condensation was detected by Hoechst 33342 staining. Proteins were detected by western blot analysis. Tumor volume was measured bidimensionally in mice inoculated with ACHN cells after vehicle or ZOL subcutaneous administration. ZOL exhibited antiproliferative effects with an $\mathrm{IC}_{50}$ value of $2.29 \pm 0.53 \mu \mathrm{M}$ in ACHN cells and chromatin condensation was observed when treated with ZOL. Farnesol (FOH) and geranylgeraniol (GGOH), precursors of farnesyl pyrophosphate and geranylgeranyl pyrophosphate, exhibited potency to rescue cells treated with ZOL. Additionally, Ras and RhoA proteins located in the membrane fraction decreased when treated with $\mathrm{ZOL}$ and recovered by $\mathrm{FOH}$ or GGOH treatment, suggesting that ZOL inhibited the mevalonate pathway, thereby suppressing the translocation of prenylated Ras and RhoA proteins to membrane fractions. An in vivo study showed the inhibitory potential of ZOL on tumor growth in mice without changes in body weight. Our study showed that ZOL could be useful as an anticancer agent for the treatment of RCC, and the mevalonate pathway could be an efficient target for novel therapeutic agents against RCC.
\end{abstract}

Correspondence to: Dr Noboru Okamura, Department of Clinical Pharmacy, School of Pharmacy and Pharmaceutical Sciences, Mukogawa Women's University, 11-68 Koshien-kyuban-cho, Nishinomiya, Hyogo 663-8179, Japan

E-mail: nokamura@mukogawa-u.ac.jp

Key words: zoledronate, mevalonate pathway, renal cell carcinoma, Ras, Rho

\section{Introduction}

Renal cell carcinoma (RCC) can be resistant to chemotherapy and radiotherapy, making nephrectomy the most effective treatment (1). Although nephrectomy can be expected to cure patients without metastatic involvement, the 5-year survival rate of those with metastasis is $<10 \%$. In addition, recent advances in drug development have allowed us to use novel agents for RCC targeting the cancer-specific pathway, such as bevacizumab, sorafenib and sunitinib (2-4). Although they prolonged overall survival in patients with advanced RCC, the effect was still insufficient; thus, it is necessary to discover novel chemotherapy for RCC. There have been studies by us and other groups, showing the possibility of other targets to treat RCC (5-7).

Bisphosphonates have been widely used for the treatment of bone disease with potent antiresorptive activity, especially nitrogen-containing bisphosphonates, including aldendronate (ALN), risedronate (RISE), and zoledronate (ZOL), which have been characterized to have strong inhibitory effects on the mevalonate pathway, thereby inhibiting the prenylation of Ras and Rho inducing cell apoptosis $(8,9)$. ZOL is the most potent nitrogen-containing bisphosphonate and it is widely used for bone diseases caused by metastasis of breast, prostate, bladder, and renal cancer $(10,11)$. In addition, ZOL has been shown to have cytotoxic effects on cancer cells, including multiple myeloma and pancreatic, colon, prostate, and breast cancer (12-18), which anticipate direct effects on cancer cells (19). In addition, ZOL has been suggested to have cytotoxic effects mediated by caspase-dependent apoptotic cell death in RCC $(20,21)$; however, limited information is available in regard to the mevalonate pathway. ZOL potency in vivo is also unknown in RCC. The aims of this study were to investigate the cytotoxic effects of ZOL in ACHN cells, derived from RCC, and to clarify the importance of the mevalonate pathway and the potency of ZOL in mice inoculated with ACHN cells.

\section{Materials and methods}

Materials. Alendronate (ALN) and Risedronate (RISE) were purchased from LKT Laboratories (St. Paul, MN), and zoledronate (ZOL) was purchased from Toronto Research 
Chemicals (Ontario, Canada). Trans, trans-farnesol (FOH), geranylgeraniol $(\mathrm{GGOH})$ and cholesterol $(\mathrm{CHO})$ were obtained from Sigma-Aldrich (St. Louis, MO). All other agents were of reagent grade.

Cell culture. ACHN, 786-O and Caki-2 cells were obtained from the Cell Resource Center for Biomedical Research Institute of Development, Aging and Cancer Tohoku University (Sendai, Japan), Summit Pharmaceuticals International (Tokyo, Japan), and DS Pharma Biomedical (Osaka, Japan), respectively, and were used as human renal carcinoma cell models. ACHN was cultured in DMEM (Wako Pure Chemical Industries, Osaka, Japan), and 786-O and Caki-2 were maintained in a culture medium consisting of RPMI-1640 (Nacalai Tesque, Kyoto, Japan). Media were supplemented with $10 \%$ heat-inactivated FBS (Invitrogen Life Technologies, Carlsbad, CA) and penicillin $(50 \mathrm{U} / \mathrm{ml})$ - streptomycin $(50 \mu \mathrm{g} / \mathrm{ml})$ (Nacalai Tesque) in an atmosphere of $5 \% \mathrm{CO}_{2}-95 \%$ air at $37^{\circ} \mathrm{C}$, and subcultured every 3 or 4 days with $0.05 \%$ trypsin / $0.2 \mathrm{mM}$ EDTA (Nacalai Tesque). The number of passages for ACHN, 786-O, and Caki-2 cells used in this study was 37-50, 15-21 and 63-69, respectively.

Cell viability. Cell viability was measured with Cell QuantiBlue $^{\mathrm{TM}}$ (BioAssay Systems, Hayward, CA). Briefly, cells were seeded onto 96-well plates (Asahi Glass, Tokyo, Japan) at a density of $2 \times 10^{3}(786-\mathrm{O})$ or $3 \times 10^{3}$ (Caki-2 and ACHN) cells/ well and incubated for $24 \mathrm{~h}$, and then treated with various concentrations of ALN, RISE or ZOL for $72 \mathrm{~h}$. The assay utilizes the conversion of Alamar Blue reagent to resorufin fluorescence by metabolically active cells and resorufin was measured with a CytoFluor ${ }^{\circledR}$ Series 4000 Fluorescence MultiWell Plate Reader (PerSeptive Biosystems, Framingham, MA) at an excitation wavelength of $530 \mathrm{~nm} /$ emission $580 \mathrm{~nm}$. IC $_{50}$ were calculated according to the sigmoid inhibitory effect model, $E=\mathrm{IC}_{50}{ }^{\gamma} /\left(\mathrm{IC}_{50}^{\gamma}+\mathrm{C}^{\gamma}\right)$. E represents the surviving fraction (\% of control), and $\mathrm{C}$ and $\gamma$ represent the drug concentration in the medium and the Hill coefficient, respectively. In addition, effects of $\mathrm{FOH}, \mathrm{GGOH}$ and $\mathrm{CHO}$ on antiproliferation induced by $3 \mu \mathrm{M}$ ZOL were examined by treating together with $5 \mu \mathrm{M}$ FOH, $5 \mu \mathrm{M}$ GGOH or $250 \mu \mathrm{M} \mathrm{CHO}$.

Detection of chromatin condensation. For nuclei staining, cells were incubated for $24 \mathrm{~h}$ after seeding, and then treated with $30 \mu \mathrm{M} \mathrm{ZOL}$ for 24,48 or $72 \mathrm{~h}$. The nuclear chromatin of trypsinzed cells was then stained with $74 \mu \mathrm{g} / \mathrm{ml}$ Hoechst 33342 (Nacalai Tesque) for $15 \mathrm{~min}$ at room temperature, and they were observed with a bright field fluorescent microscope (Vanox; Olympus, Tokyo, Japan) under UV excitation. The percentage of chromatin-condensed cells was determined by counting $>450$ cells in each experiment.

Western blotting. Cells were seeded at a density of $5 \times 10^{5}$ cells/ dish and incubated for $24 \mathrm{~h}$. They were then treated with ZOL alone or together with FOH or GGOH for $72 \mathrm{~h}$, harvested by scraping and rinsed twice with ice-cold phosphate-buffered saline (PBS). The cell pellets were suspended in lysis buffer 1 (50 mM HEPES (pH 7.4), $50 \mathrm{mM} \mathrm{NaCl}, 1 \mathrm{mM} \mathrm{MgCl} 2,2 \mathrm{mM}$ EDTA, $1 \mathrm{mM}$ phenylmethylsulfonyl fluoride, $10 \mu \mathrm{g} / \mathrm{ml}$ leupeptin, $1 \mathrm{mM} \mathrm{Na} \mathrm{VO}_{4}, 5 \mathrm{mM} \mathrm{NaF}, 1 \mathrm{mM}$ dithiothreitol,
$0.1 \%(w / v)$ Triton X-100) with a sonicator, then left to stand on ice for $10 \mathrm{~min}$, followed by ultracentrifugation at $24,000 \mathrm{x} \mathrm{g}$ for 15 min with a Beckman Coulter Optima XL-100K ultracentrifuge (Beckman Coulter, Tokyo, Japan). The supernatants were subjected to western blot analysis as cytosol samples. Lysis buffer 2 (50 mM HEPES (pH 7.4), $50 \mathrm{mM} \mathrm{NaCl}, 1 \mathrm{mM}$ $\mathrm{MgCl}_{2}, 2 \mathrm{mM}$ EDTA, $1 \mathrm{mM}$ phenylmethylsulfonyl fluoride, $10 \mu \mathrm{g} / \mathrm{ml}$ leupeptin, $1 \mathrm{mM} \mathrm{Na}_{3} \mathrm{VO}_{4}, 5 \mathrm{mM} \mathrm{NaF}, 1 \mathrm{mM}$ dithiothreitol, $1 \%(\mathrm{w} / \mathrm{v})$ Triton X-100) were added to the pellets followed by sonication, then left to stand on ice for $10 \mathrm{~min}$, followed by ultracentrifugation at $24,000 \mathrm{x}$ g for $15 \mathrm{~min}$. The supernatants were subjected to Western blot analysis as membrane samples.

The samples were mixed with the same volume of Laemmli sample buffer (Bio-Rad Laboratories, Hercules, CA) including 5\% $\beta$-mercaptoethanol, and then boiled for $5 \mathrm{~min}$. Protein $(7 \mu \mathrm{g})$ was fractionated by $12.5 \%$ SDS-PAGE, transferred to PVDF membrane (ATTO, Tokyo, Japan) and blocked with Tris-buffered saline, including ECL Advance ${ }^{\mathrm{TM}}$ blocking reagent (GE Healthcare, Buckinghamshire, UK). Seven micrograms of protein were analyzed using mouse anti-Ras (BD Biosciences, San Jose, CA), mouse anti-RhoA, and mouse anti- $\beta$-actin antibodies (Santa Cruz Biotechnology, Santa Cruz, CA). Horseradish peroxidase-conjugated secondary antibody against mouse IgG (GE Healthcare) was used at 1:25000 dilution with the blocking buffer, and the signals were visualized using ECL Advance detection reagents (GE Healthcare) according to the manufacturer's procedure. Protein concentrations were determined with the BCA Protein Assay Reagent kit (ThermoFisher Scientific, Waltham, MA), and bovine serum albumin was used for the standard curve.

Animal model. Animal experiments were performed in accordance with the guidelines of the Institutional Animal Use Committee of Mukogawa Women's University, and the procedure was approved by the Committee. Balb/c male mice (4 weeks old) were purchased from Japan SLC (Shizuoka, Japan), and subcutaneously inoculated in the back with ACHN cells $\left(1 \times 10^{7}\right.$ cells $/ 100 \mu 1$ in PBS). Ten days after inoculation, ZOL was subcutaneously administered in the abdomen at a dose of $0.5 \mathrm{mg} / \mathrm{kg} / 100 \mu \mathrm{l}$ in PBS once a week for five weeks. Tumor size was measured bidimensionally and volume was calculated by the formula (length $\mathrm{x}$ width $\left.^{2}\right) / 2$. Mouse weight was also monitored.

Statistics. The data are expressed as the mean \pm SD. Statistical analysis was performed with Student's t-test for comparison of two groups and non-repeated one-way ANOVA followed by Dunnett's post hoc test for multiple comparison. $\mathrm{P}<0.05$ was considered significant.

\section{Results}

Effects of bisphosphonates (ALN, RISE and ZOL) on RCC cells. Fig. 1 shows the effects of ALN, RISE or ZOL on the proliferation in three RCC cell lines, and Table I shows the $\mathrm{IC}_{50}$ values. All the bisphosphonates inhibited cell growth in a concentration-dependent manner, with $\mathrm{IC}_{50}$ values of 19-156 $\mu \mathrm{M}$ for ALN, 99-329 $\mu \mathrm{M}$ for RISE, and 2-18 $\mu \mathrm{M}$ for 

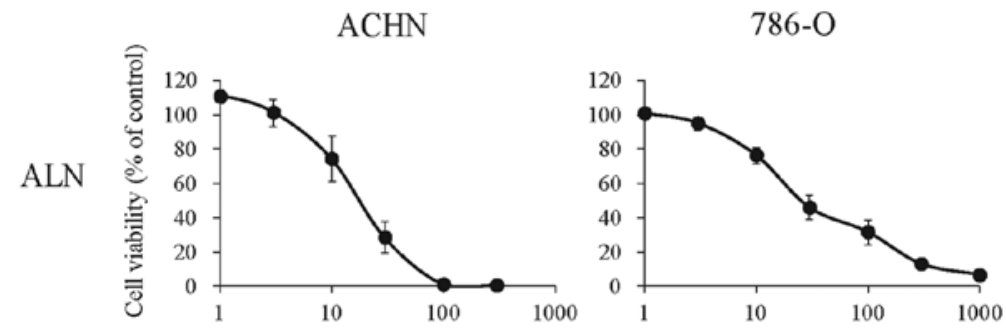

Caki-2
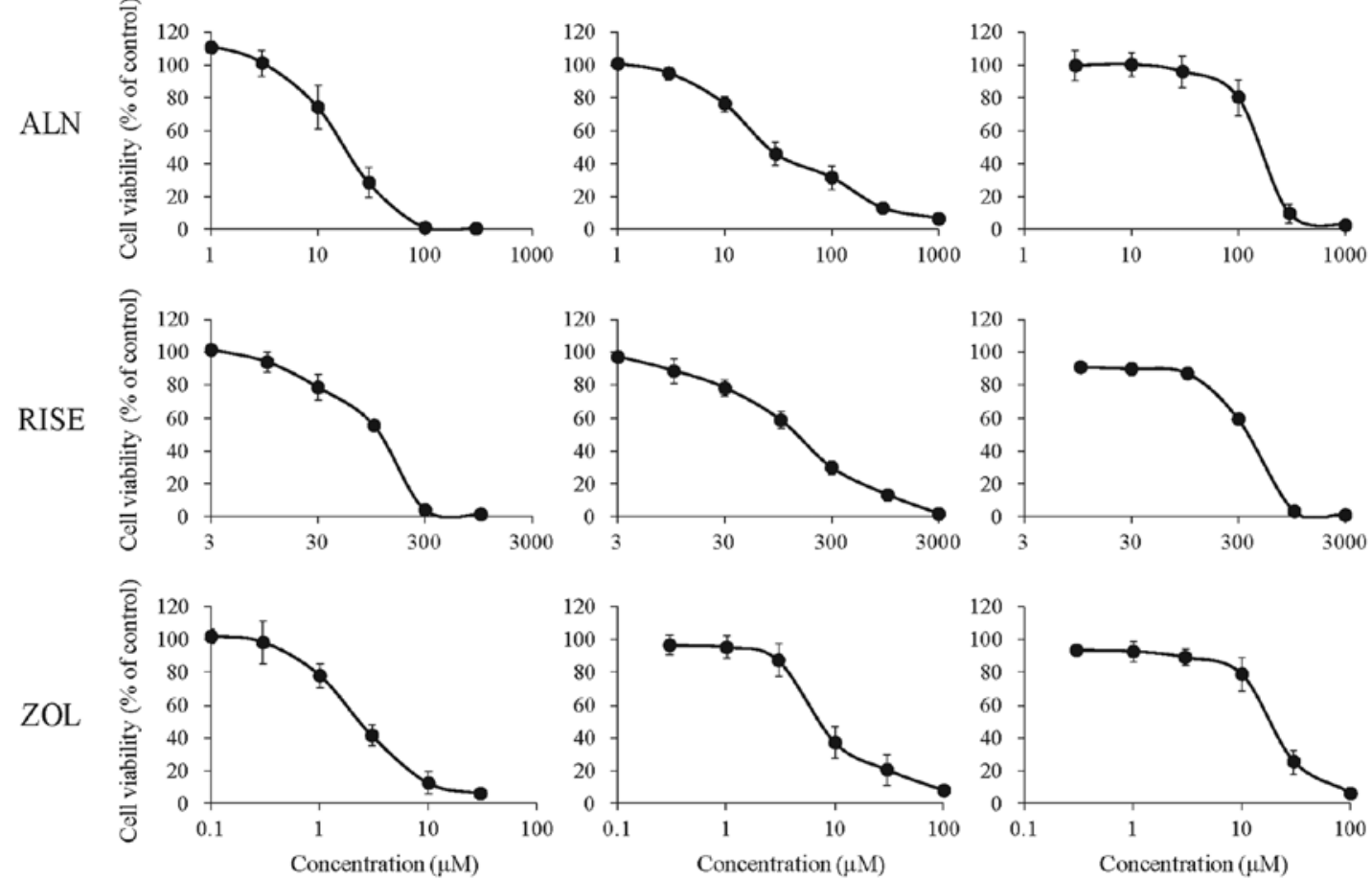

Figure 1. Antiproliferative effects of bisphosphonates (ALN, RISE and ZOL) on RCC cells. Cells were precultured for $24 \mathrm{~h}$ at a density of $2 \times 10^{3}$ (786-O) or $3 \times 10^{3}$ (Caki-2 and ACHN) cells/well in 96-well plates and treated with ALN, RISE or ZOL for $72 \mathrm{~h}$. Cell viability was determined by fluorescent assay. Data are the mean \pm SD of three to five experiments.

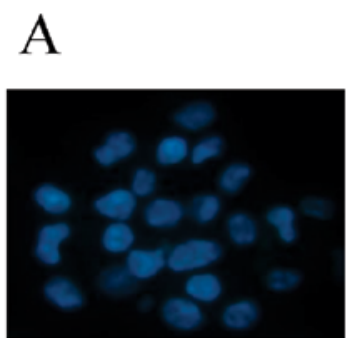

Control

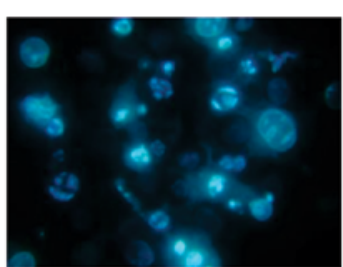

ZOL $(30 \mu \mathrm{M})$

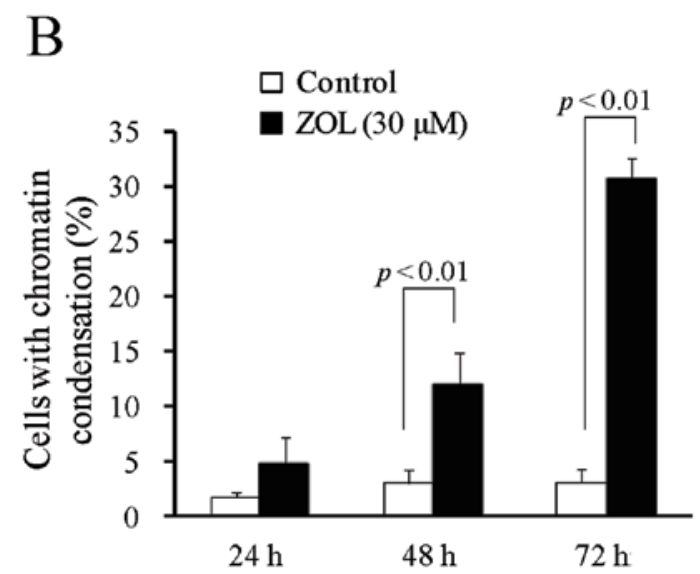

Figure 2. Typical fluorescence microscopy images (A) and \% of cells with chromatin condensation (B) of ACHN cells treated with ZOL. Cells were precultured for $24 \mathrm{~h}$ at a density of $5 \times 10^{5}$ cells/100-mm dish and treated with $30 \mu \mathrm{M}$ ZOL for 24,48 and $72 \mathrm{~h}$. They were then stained with Hoechst 33342 and observed under a brightfield fluorescent microscope under UV excitation, and \% of cells with chromatin condensation was counted. Data are the mean \pm SD of four experiments.
Table I. $\mathrm{IC}_{50}$ values for bisphosphonates in ACHN, 786-O and Caki-2 cells.

\begin{tabular}{lcrr}
\hline & ACHN & \multicolumn{1}{c}{$786-\mathrm{O}$} & \multicolumn{1}{c}{ Caki-2 } \\
\hline ALN $(\mu \mathrm{M})$ & $18.8 \pm 5.95$ & $35.2 \pm 6.14$ & $156 \pm 27.3$ \\
RISE $(\mu \mathrm{M})$ & $99.1 \pm 7.68$ & $130 \pm 22.9$ & $329 \pm 8.93$ \\
ZOL $(\mu \mathrm{M})$ & $2.29 \pm 0.53$ & $8.43 \pm 2.29$ & $18.3 \pm 3.85$
\end{tabular}

Cells were precultured for $24 \mathrm{~h}$ at a density of $2 \times 10^{3}(786-\mathrm{O})$ or $3 \times 10^{3}$ (Caki-2 and ACHN) cells/well in 96-well plates and treated with ALN, RISE or ZOL for $72 \mathrm{~h}$. Cell viability was determined by fluorescent assay and $\mathrm{IC}_{50}$ values were calculated. Data are the mean $\pm \mathrm{SD}$ of three to five experiments.

ZOL in three RCC cell lines. ZOL exhibited the strongest effect on the proliferation in three RCC, in ACHN cells with $\mathrm{IC}_{50}$ value of $2.29 \pm 0.53 \mu \mathrm{M}$.

When cells were exposed to $30 \mu \mathrm{M} \mathrm{ZOL}$, chromatin condensation, a typical morphological change in apoptosis, was found after staining with Hoechst 33342 (Fig. 2A). The percentages of cells with chromatin condensation significantly increased by ZOL treatment time-dependently (Fig. 2B).

Effects of $\mathrm{FOH}, \mathrm{GGOH}$ and $\mathrm{CHO}$ on antiproliferation induced by zoledronate. To clarify the role of the mevalonate pathway in the antiproliferative effects of $\mathrm{ZOL}$, we investigated the effects of $\mathrm{FOH}$ and GGOH, precursors of farnesyl pyrophosphate and geranylgeranyl pyrophosphate, on cell survival. As a result, FOH and GGOH attenuated the antiproliferative 


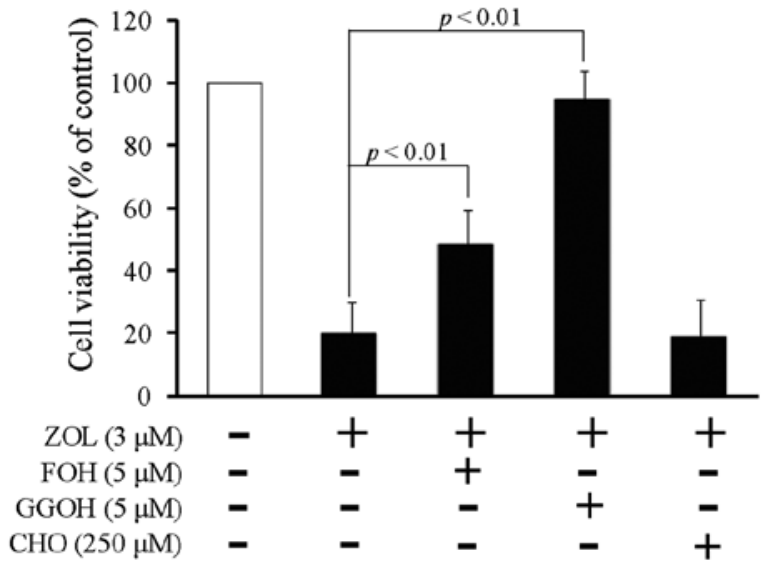

Figure 3. Effects of FOH and GGOH on antiproliferatative effects induced by ZOL in ACHN cells. Cells were precultured for $24 \mathrm{~h}$ at a density of $3 \times 10^{3}$ cells/well in 96-well plates and treated with ZOL in the presence or absence of $\mathrm{FOH}, \mathrm{GGOH}$ or $\mathrm{CHO}$ for $72 \mathrm{~h}$. Cell viability was determined by fluorescent assay. Data are the mean \pm SD of three or four experiments.
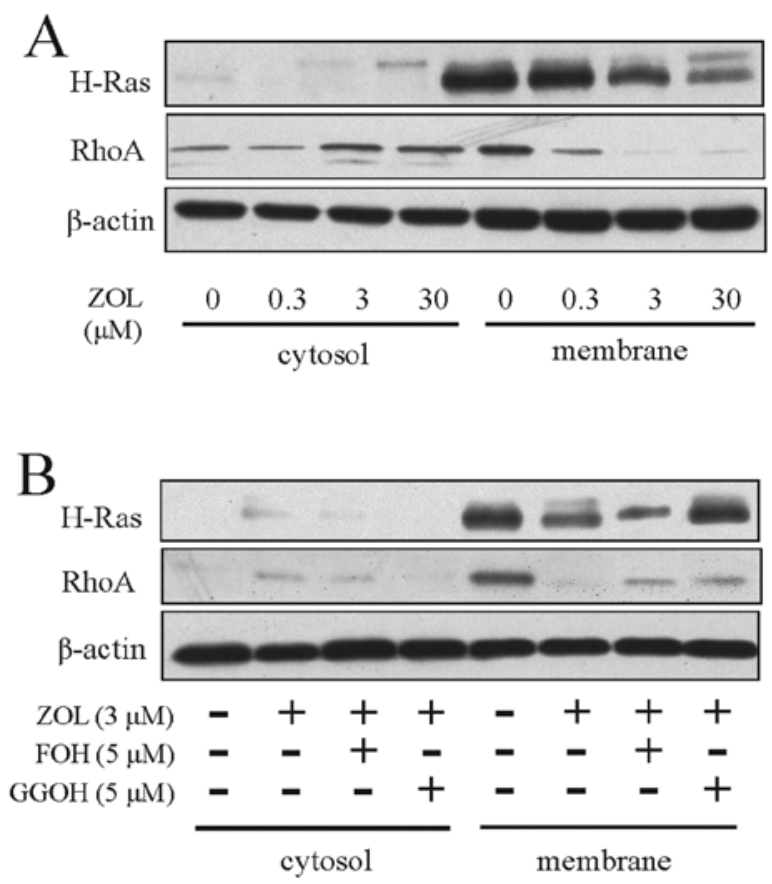

Figure 4. Alteration of cytosolic and membrane anchored Ras and RhoA by ZOL (A) and effect of FOH or GGOH on the alteration (B) in ACHN cells. Cells were precultured for $24 \mathrm{~h}$ at a density of $5 \times 10^{5}$ cells/100-mm dish and treated with ZOL in the presence or absence of FOH or GGOH for $72 \mathrm{~h}$. Cells were then fractionated by ultracentrifugation and $7 \mu \mathrm{g}$ proteins were analyzed by western blot analysis for Ras and RhoA.

effects of ZOL (Fig. 3). Furthermore, CHO had no effect on cell survival.

Next, we investigated the localization of Ras and RhoA proteins when cells were treated with ZOL. Their inactive forms are primary localized in cytosol, which can be translocated to the membrane as active forms after prenylation with isoprenoid provided by farnesyl pyrophosphate or geranylgeranyl pyrophosphate. Fig. 4A shows that Ras and RhoA proteins located at the membrane decreased with ZOL treatment in a concentration-dependent manner while they
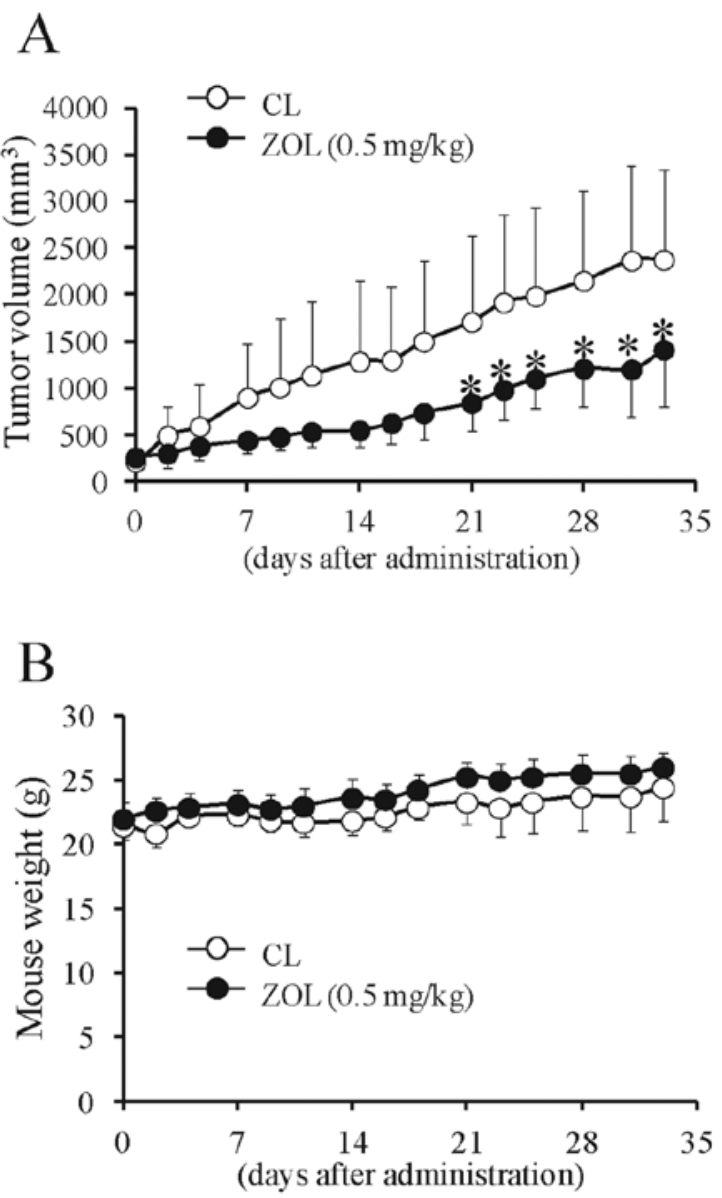

Figure 5. Effects of ZOL on tumor volume (A) and body weights (B) in mice inoculated with ACHN cells. Mice were subcutaneously inoculated in the back with $1 \times 10^{7}$ cells of ACHN 10 days before the start of ZOL administration. Mice were then subcutaneously injected in the abdomen once a week with vehicle (control; CL, $\mathrm{n}=7$ ) or $0.5 \mathrm{mg} / \mathrm{kg}$ of ZOL $(\mathrm{n}=8)$ for 5 weeks. Data are the mean \pm SD. ${ }^{*} \mathrm{p}<0.05$, significantly different from the CL group.

increased in cytosol. In addition, treatment with $\mathrm{FOH}$ and GGOH recovered proteins in the membrane (Fig. 4B).

Effects of zoledronate on proliferation of ACHN inoculated in mice. To clarify the effects of ZOL in controlling tumor growth, we investigated the effects of $\mathrm{ZOL}$ administration on mice inoculated with ACHN cells. ZOL exhibited inhibitory effects on tumor growth in the ACHN xenograft model (Fig. 5A), while the body weights of mice were not changed compared with the vehicle administration group (Fig. 5B).

\section{Discussion}

Nephrectomy is still a common treatment for RCC, known to be resistant to chemotherapy and radiotherapy, although novel agents, including bevacizumab, sorafenib and sunitinib, prolonged the survival rate (1-4). ZOL has been shown to have cytotoxic effects on cancer cells, including multiple myeloma and pancreatic, colon, prostate and breast cancer (12-18). In addition, ZOL has been suggested to have cytotoxic effects on $\operatorname{RCC}(19,20)$.

We clearly showed that three bisphosphonates, ALN, RISE and ZOL, showed antiproliferative effects on three RCC cell 
lines (Fig. 1, Table I). However, ZOL showed the inhibitory effects most potently of the three drugs, and ACHN cells were the most sensitive to each drug in three cell lines. Therefore, we chose the most effective combination, $\mathrm{ZOL}$ and $\mathrm{ACHN}$, for further investigations.

ZOL showed antiproliferative effects on ACHN cells with an $\mathrm{IC}_{50}$ value of $2.29 \pm 0.53 \mu \mathrm{M}$ (Fig. 1), which was comparable or somewhat stronger than the data by Ullén et al, who reported that $69 \%$ viable cells were found at $12.5 \mu \mathrm{M}$ ZOL for $72 \mathrm{~h}$ in ACHN cells (21). Skerjanec et al reported that the maximum concentration of ZOL was 300-400 $\mathrm{ng} / \mathrm{ml}$ (ca. 1-1.3 $\mu \mathrm{M}$ ) after infusion of $4 \mathrm{mg} Z \mathrm{ZOL}$ (22). Although renal distribution was not available in humans, it is likely to reach the concentrations in the clinical setting.

Next, we examined the involvement of apoptosis in the effects of ZOL. Chromatin condensation was found in ACHN cells treated with ZOL in a time-dependent manner (Fig. 2), suggesting that ZOL induced apoptosis at least in part. Pandha et al and Ullén et al reported that ZOL induced apoptotic cell death in a caspase-dependent manner; however, they did not examine the involvement of the mevalonate pathway $(20,21)$, although there have been reports suggesting that the mevalonate pathway is important for the mechanisms of cell death induced by bisphosphonates in multiple myeloma, prostate cancer and breast cancer (23-25).

The mevalonate pathway plays an important role in synthesizing farnesyl pyrophosphate, geranylgeranyl pyrophosphate and cholesterol $(8,9,19,26)$. In particular, farnesyl pyrophosphate and geranylgeranyl pyrophosphate provide isoprenoid in the prenylation of Ras and Rho; thereby, they are translocated to the membrane as active forms, regulating cell progression and cell death (19). To clarify the contribution of the inhibition of the mevalonate pathway in ZOL-induced antiproliferative effects in RCC, effects of $\mathrm{FOH}$ and $\mathrm{GGOH}$ were examined in ACHN cells treated with ZOL. As a result, FOH and GGOH significantly recovered cell survival (Fig. 3). It has been also reported that the depletion of cholesterol induced cell apoptosis in prostate cancer and embryonic fibroblast cell $(27,28)$, but we did not observe a change of cell survival with cholesterol treatment. Accordingly, it was suggested that the antiproliferative effects of ZOL were due to inhibition of the synthesis of farnesyl pyrophosphate, while cholesterol depletion was not involved in antiproliferation.

Also, we found a decrease of Ras and RhoA proteins localized in the membrane fraction in ACHN cells treated with ZOL in a concentration-dependent manner, and $\mathrm{FOH}$ and GGOH recovered the amount of Ras and RhoA proteins at membranes (Fig. 4). Nogawa et al reported that the ZOL-induced growth inhibitory effect was circumvented by the addition of GGOH but not $\mathrm{FOH}$ in prostate cancer cells and that the amount of membrane-anchored Ras was independent of ZOL-induced growth inhibition, suggesting that geranylgeranylation was more important than farnesylation (18). We observed a stronger effect of the addition of GGOH on the antiproliferative effects of ZOL; however, our data showed that the ZOL-induced antiproliferative effect was dependent on the amount of Ras protein localized at membranes. The reason for this discrepancy was unclear but at least the Ras signal was important for the proliferation of RCC, although it was not in prostate cancer cells. Collectively, inhibition of the mevalonate pathway by ZOL induced the decreased prenylation of Ras and Rho proteins, which led to decreased active forms of Ras and Rho located at the membrane.

Next, we evaluated the antitumor effects of ZOL administration in mice inoculated with ACHN cells. Tumor growth was significantly inhibited by the administration of ZOL, while the body weights of mice did not change (Fig. 5), suggesting that marked adverse effects did not occur in this condition. Thus, efficient therapeutic effects of ZOL could be expected for the treatment of RCC.

In conclusion, it was demonstrated that ZOL inhibited the proliferation of ACHN cells and suggested that ZOL inhibited the mevalonate pathway, thereby suppressing the translocation of prenylated Ras and Rho proteins to membrane fractions. ZOL was shown to inhibit tumor growth in mice inoculated with ACHN cells in vivo; therefore, our study showed that ZOL could be useful as an anticancer agent for the treatment of RCC, and the mevalonate pathway could be an efficient target for novel therapeutic agents against RCC.

\section{Acknowledgements}

This study was supported in part by Grants-in-Aid for Scientific Research from the Ministry of Education, Culture, Sports, Science and Technology, Japan.

\section{References}

1. Amato RJ: Renal cell carcinoma: review of novel single-agent therapeutics and combination regimens. Ann Oncol 16: 7-15, 2005.

2. Garcia JA and Rini BI: Recent progress in the management of advanced renal cell carcinoma. CA Cancer J Clin 57: 112-125, 2007.

3. Gore ME and Larkin JMG: Challenges and opportunities for converting renal cell carcinoma into a chronic disease with targeted therapies. Br J Cancer 104: 399-406, 2011.

4. Di Lorenzo G, Buonerba C, Biglietto M, et al: The therapy of kidney cancer with biomolecular drugs. Cancer Treat Rev 36: S16-S20, 2010.

5. Fujita M, Yagami T, Fujio M, et al: Cytotoxicity of troglitazone through PPAR $\gamma$-independent pathway and p38 MAPK pathway in renal cell carcinoma. Cancer Lett 312: 219-227, 2011.

6. Elfiky AA, Aziz SA, Conrad PJ, et al: Characterization and targeting of phosphatidylinositol-3 kinase (PI3K) and mammalian target of rapamycin (mTOR) in renal cell cancer. J Transl Med 11: $133,2011$.

7. Flaherty KT and Puzanov I: Building on a foundation of VEGF and mTOR targeted agents in renal cell carcinoma. Biochem Pharmacol 80: 638-646, 2010.

8. Russell RG, Xia Z, Dunford JE, et al: Bisphosphonates: an update on mechanisms of action and how these relate to clinical efficacy. Ann NY Acad Sci 1117: 209-257, 2007.

9. Russell RG, Watts NB, Ebetino FH and Rogers MJ: Mechanisms of action of bisphosphonates: similarities and differences and their potential influence on clinical efficacy. Osteoporos Int 19: 733-759, 2008.

10. Dhillon S and Lyseng-Williamson KA: Zoledronic acid: a review of its use in the management of bone metastases of malignancy. Drugs 68: 507-534, 2008.

11. Saad F and Eastham JA: Zoledronic acid use in patients with bone metastases from renal cell carcinoma or bladder cancer. Semin Oncol 37: S38-S44, 2010.

12. Iguchi T, Miyakawa Y, Yamamoto K, Kizaki M and Ikeda Y: Nitrogen-containing bisphosphonates induce S-phase cell cycle arrest and apoptosis of myeloma cells by activating MAPK pathway and inhibiting mevalonate pathway. Cell Signal 15: 719-727, 2003.

13. Tassone $\mathrm{P}$, Tagliaferri $\mathrm{P}$, Viscomi $\mathrm{C}$, et al: Zoledronic acid induces antiproliferative and apoptotic effects in human pancreatic cancer cells in vitro. Br J Cancer 88: 1971-1981, 2003. 
14. Sewing L, Steinberg F, Schmidt H and Göke R: The bisphosphonate zoledronic acid inhibits the growth of HCT-116 colon carcinoma cells and induces tumor cell apoptosis. Apoptosis 13: 782-789, 2008

15. Almubarak H, Jones A, Chaisuparat R, Zhang M, Meiller TF and Scheper MA: Zoledronic acid directly suppresses cell proliferation and induces apoptosis in highly tumorigenic prostate and breast cancers. J Carcinog 10: 2, 2011

16. Merrell MA, Wakchoure S, Lehenkari PP, Harris KW and Selander KS: Inhibition of the mevalonate pathway and activation of p38 MAP kinase are independently regulated by nitrogencontaining bisphosphonates in breast cancer cells. Eur J Pharmacol 570: 27-37, 2007.

17. Rachner TD, Singh SK, Schoppet M, et al: Zoledronic acid induces apoptosis and changes the TRAIL/OPG ratio in breast cancer cells. Cancer Lett 287: 109-116, 2010.

18. Nogawa M, Yuasa T, Kimura S, et al: Zoledronic acid mediates Ras-independent growth inhibition of prostate cancer cells. Oncol Res 15: 1-9, 2005.

19. Fritz G: Targeting the mevalonate pathway for improved anticancer therapy. Curr Cancer Drug Targets 9: 626-638, 2009.

20. Pandha H, Birchall L, Meyer B, et al: Antitumor effects of aminobisphosphonates on renal cell carcinoma cell lines. J Urol 176: 2255-2261, 2006.

21. Ullén A, Schwarz S, Lennartsson L, et al: Zoledronic acid induces caspase-dependent apoptosis in renal cancer cell lines. Scand J Urol Nephrol 43: 98-103, 2009.
22. Skerjanec A, Berenson J, Hsu C, et al: The pharmacokinetics and pharmacodynamics of zoledronic acid in cancer patients with varying degrees of renal function. J Clin Pharmacol 43: 154-162, 2003.

23. Shipman CM, Croucher PI, Russell RG, Helfrich MH and Rogers MJ: The bisphosphonate incadronate (YM175) causes apoptosis of human myeloma cells in vitro by inhibiting the mevalonate pathway. Cancer Res 58: 5294-5297, 1998.

24. Virtanen SS, Väänänen HK, Härkönen PL and Lakkakorpi PT: Alendronate inhibits invasion of PC-3 prostate cancer cells by affecting the mevalonate pathway. Cancer Res 62: 2708-2714, 2002.

25. Räikkönen J, Mönkkönen H, Auriola S, Harris KW and Selander KS: Mevalonate pathway intermediates downregulate zoledronic acid-induced isopentenyl pyrophosphate and ATP analog formation in human breast cancer cells. Biochem Pharmacol 79: 777-783, 2010.

26. Miziorko HM: Enzymes of the mevalonate pathway of isoprenoid biosynthesis. Arch Biochem Biophys 505: 131-143, 2011.

27. Zhuang L, Kim J, Adam RM, Solomon KR and Freeman MR: Cholesterol targeting alters lipid raft composition and cell survival in prostate cancer cells and xenografts. J Clin Invest 115: 959-968, 2005.

28. Calleros L, Lasa M, Rodríguez-Alvarez FJ, Toro MJ and Chiloeches A: RhoA and p38 MAPK mediate apoptosis induced by cellular cholesterol depletion. Apoptosis 11: 1161-1173, 2006. 